\title{
Comparing the Effect of Sodium Valproate and Carbamazepine on Sexual Function Satisfaction in Men with Epilepsy in Hamadan City
}

\author{
Mehrdokht Mazdeh (MD) ${ }^{1, *}$, Masoud Ghiasian (MD) ${ }^{1}$, Shahir Mazaheri (MD) ${ }^{1}$, \\ Mohammad Faryadras (MSc) ${ }^{2}$
}

${ }^{I}$ Department of Neurology, School of Medicine, Hamadan University of Medical Sciences, Hamadan, Iran

${ }^{2}$ Department of Biostatistics and Epidemiology, School of Public Health, Hamadan University of Medical Sciences, Hamadan, Iran

* Corresponding Author: Mehrdokht Mazdeh, Department of Neurology, School of Medicine, Hamadan University of Medical Sciences, Hamadan, Iran. Email: mehrdokhtmazdeh@yahoo.com

\begin{tabular}{l} 
Received: $17 / 04 / 2017$ \\
Accepted: $17 / 01 / 2018$ \\
\hline How to Cite this Article: \\
Mazdeh M, Ghiasian M, Mazaheri \\
Sh, Faryadras M. Comparing the \\
Effect of Sodium Valproate \\
and Carbamazepine on Sexual \\
Function Satisfaction in Men \\
with Epilepsy in Hamadan City. \\
Pajouhan Scientific Journal. \\
2018; 16(2): 53-58. DOI: \\
10.21859/psj.16.2.53
\end{tabular}

\section{Abstract}

Background and Objective: Although antiepileptic drugs have controlled the epilepsy attacks substantially, the side-effects are still considered as a problem to the patients. The aim of this study was to compare the effects of sodium valproate and carbamazepine on sexual function in men with epilepsy.

Materials and Methods: In this cross-sectional study 35 male married epileptic patients with the history of taking carbamazepine for at least one year and 35 other male married patients using sodium valproate for at least one year have been participated. Both groups' sexual activity information has been evaluated by international index of erectile questionnaire. This fifteen question survey has investigated men's sexual activity in 5 fields such as erectile function, orgasmic function, sexual desire, intercourse satisfaction and overall satisfaction. Each question has 5 scores at most and the total score of the survey comes to 75.The results have been analyzed by Chi-Square and Mann-Whitney U tests using the statistical software SPSS (ver.16.0).

Results: The average of total gained scores in sodium valproate takers was more than carbamazepine takers $(51.68,53.42)$ but there was no significant difference $(\mathrm{p}=0.582)$. Twenty-five sodium valproate takers $(48.1 \%)$ and twenty-seven carbamazepine takers $(51.9 \%)$ had erectile function disorder but there was no significant difference $(\mathrm{p}=0.584)$. The sodium valproate group average scores in all sexual activity fields except sexual desire was more than carbamazepine group but there was significant difference regarding only sexual desire.

Conclusion: Sexual activity disorders in men with epilepsy, especially erectile disorder were highly prevalent and also the result showed that patients who take sodium valproate had better status than carbamazepine takers regard to sexual activities except sexual desire.

Keywords: Carbamazepine; Epilepsy; Sexual Activity; Sodium Valproate 
do): $10.21859 /$ psj. 16.2 .53

\section{مقايسه اثر داروى سديم واليروات و كاربامازبين بر عملكرد جنسى در بيماران مصروع} ملنكر شهر همدان

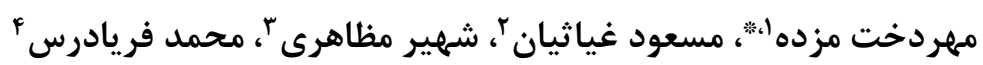
' استاد نورولوزى، دانشكاه علوم يزشكى همدان، همدان، ايران

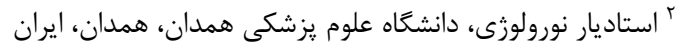

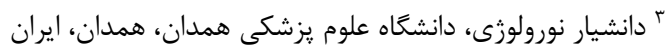

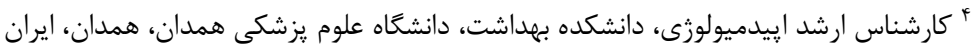
* نويسنده مسئول: مهردخت مزده، دانشخاه علوم يزشكى همدان، همدان، ايران. ايميل: mehrdokhtmazdeh@yahoo.com

\begin{tabular}{|c|c|}
\hline 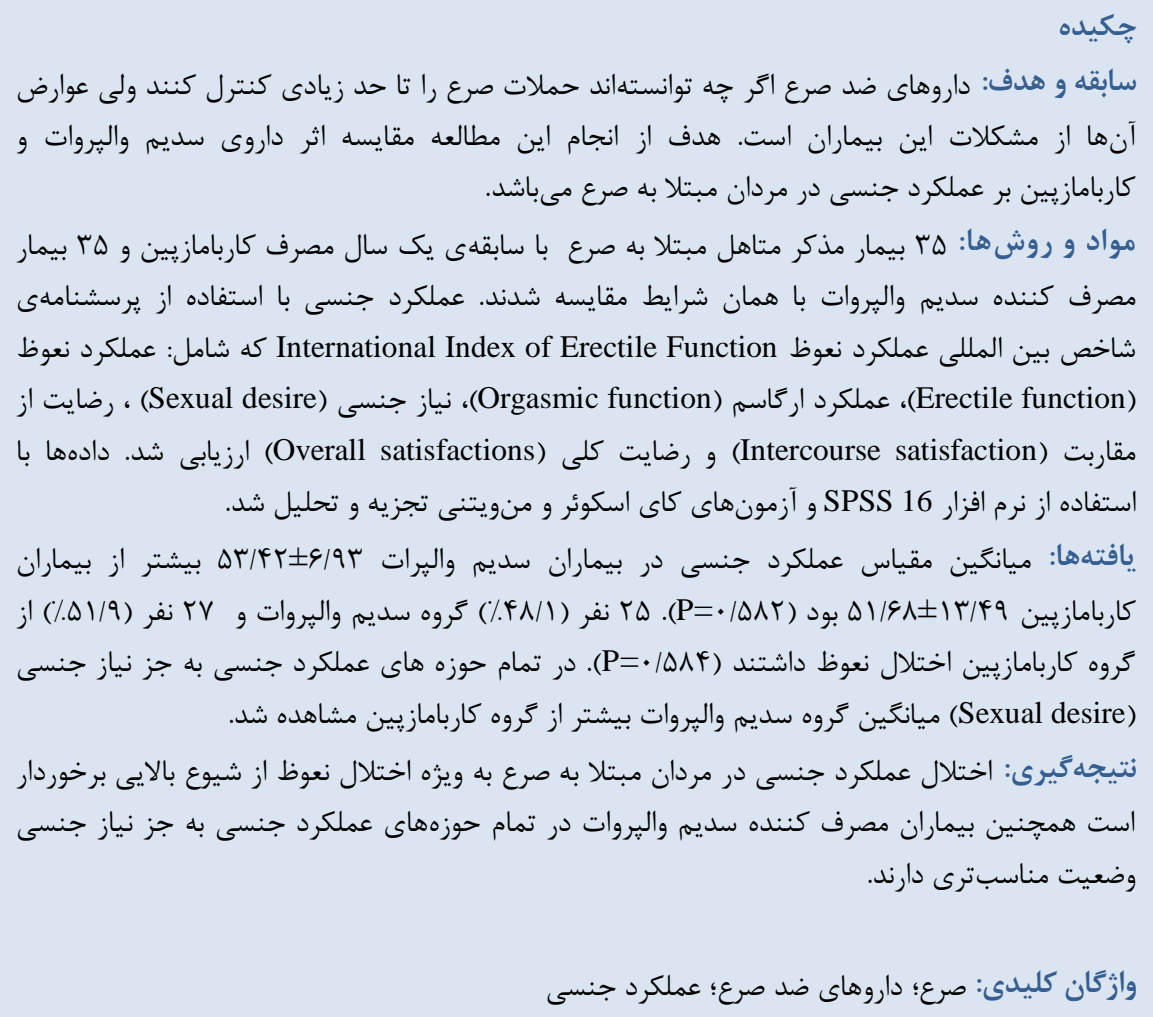 & 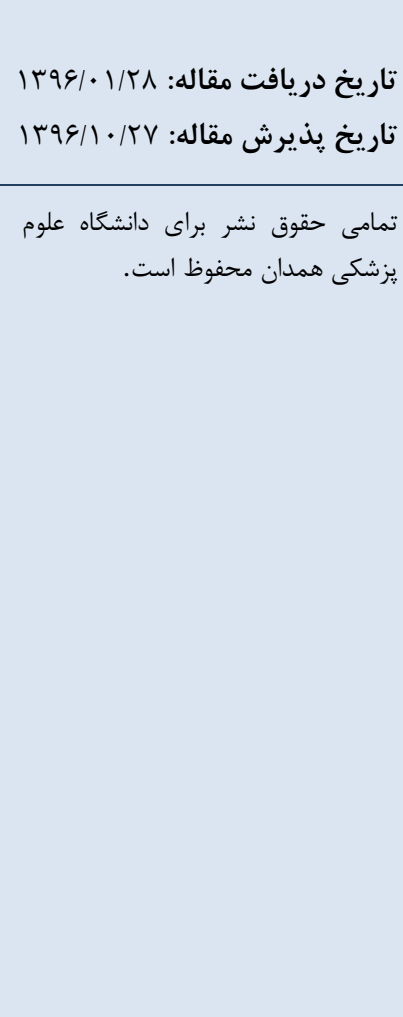 \\
\hline
\end{tabular}

جمعيت نرمال تخمين زده شده است. شايعترين اختلالات

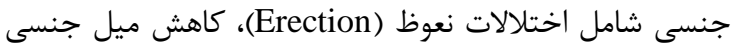
(Libido)

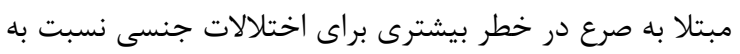

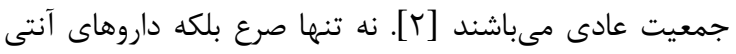

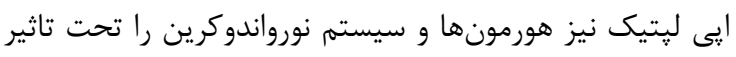

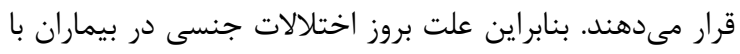

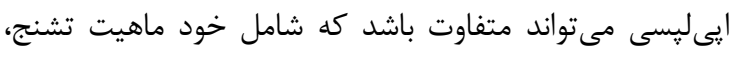

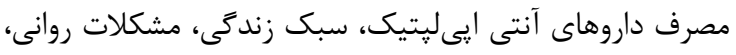
مجله علمى بزوهان، دوره 19، شماره ז، زمستان وه"ا
صرع (Epilepsy) بيمارى مزمن، ناتوان كننده و شايعترين

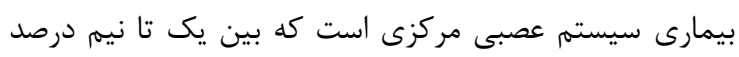

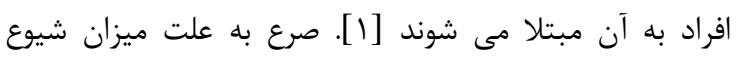

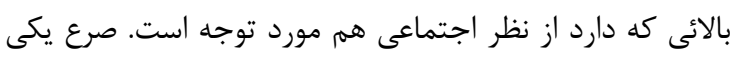

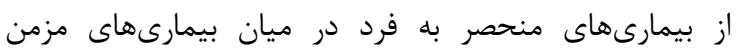

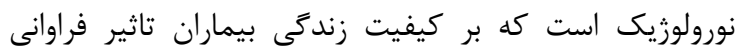
مى گذارد و ممكن است بر كاهش فعاليتهاى اجتماعى افراد

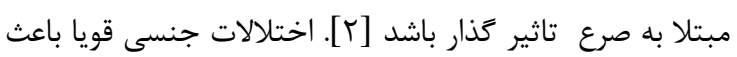

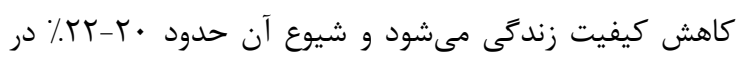


شد. با استفاده از نتايج مطالعه Heroz AG و همكاران [ᄉ]

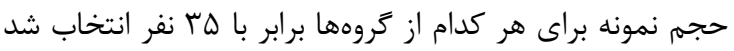

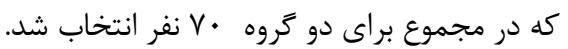

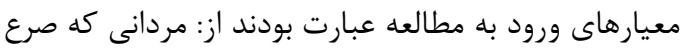

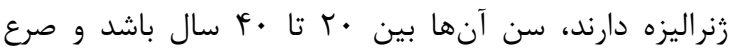

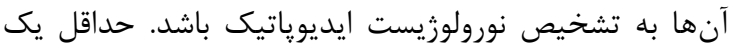

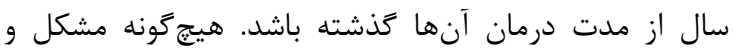

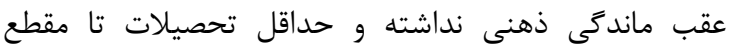
راهنمايى را داشته باشند. افراد با سابقهى اختلال اندوكرين

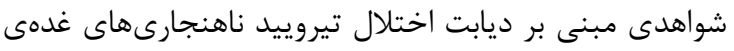
هييوفيز سابقه بيمارىهاى روان يزشكى دئى موثر بر عملكرد

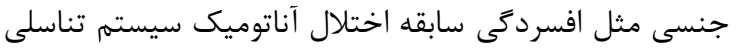
سابقه بيمارىهاى اورولوزيك موثر بر عملكرد جنسى مثل مثل

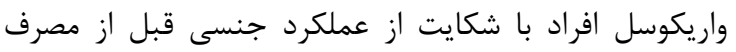
دارو مصرف داروهاى موثر بر عملكرد جنسى مثل SSRI ها،

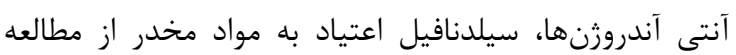

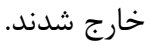

جهت ارزيابى عملكرد جنسى از يرسشنامهى شاخص بين

المللى عملكرد نعوظ ( International Index of Erectile (Function

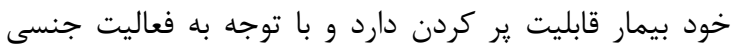

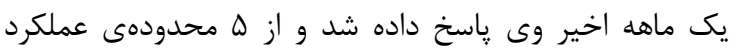

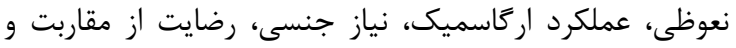

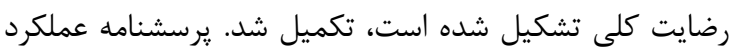
جنسى مردان يك يرسشنامه ها سوالى جهت سنجش عملكرد جنسى مردان است. پاسخها در آن به صورت ليكان ليكرتى سنجش

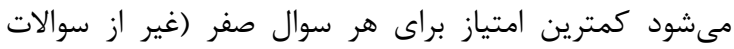

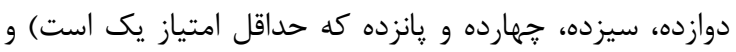
بيشترين ه است (نمره ينج براى عملكرد طبيعى) و سؤالها، ودها،

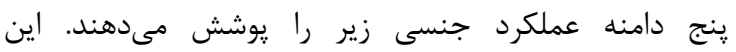

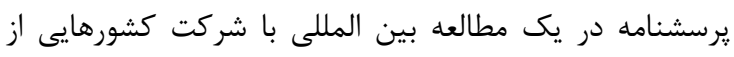

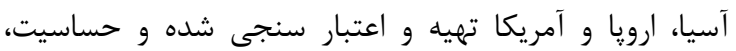

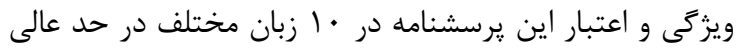
ارزيابى شده است [9]. براى مقايسه ميانخين متغييرهاى كمى ونى

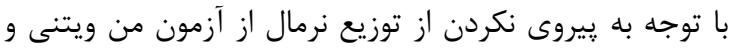

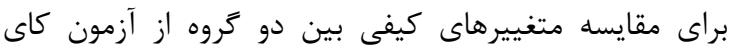

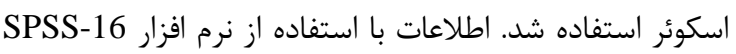
مورد تجزيه و تحليل قرار كرفت.

بافْته.

ميانگين سنى افراد دريافت كننده سديم واليروات برابر با

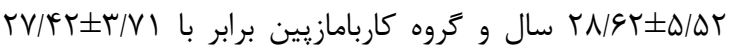

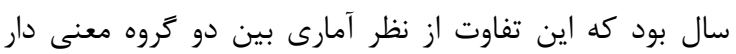

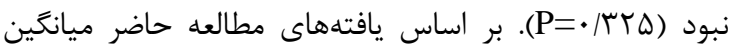

اثر اختلال الكتريكى مغز بر ناحيه اى از مغز كه بر روى رفتار جنسى تاثير دارد و يا حتى وجود همزمان مشكلات ديخر جنسى كه ارتباطى با تشنج ندارند. شناخت دقيق اينكه كدام

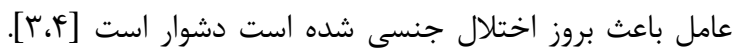
مطالعات بر روى اثرات AEDs بر روى عملكرد جنسى و ميزان

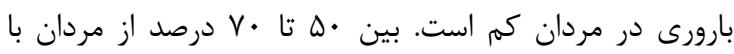

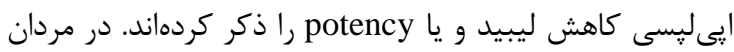

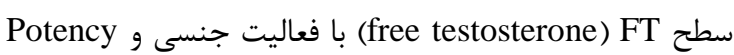
ارتباط مستقيم دارد و همجنين هرجه سطح استراديول افزايش

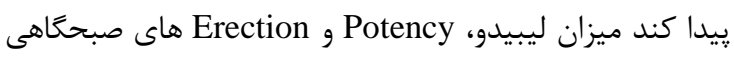
كاهش مىيابد. در مردان با إيى ليسى سطح استراديول افزايش

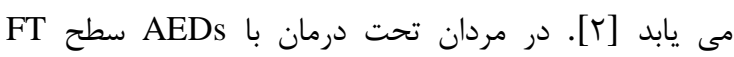

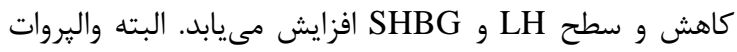
سديم اين اثر را ايجاد نمىكند [ه]]. هنوز در مورد شيوع

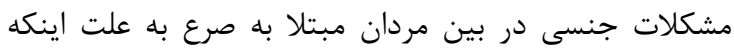

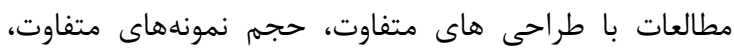

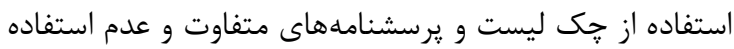

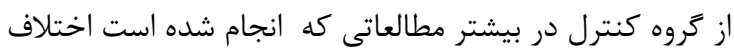

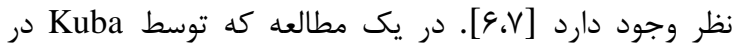

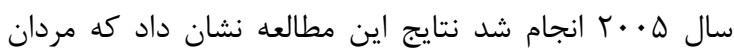

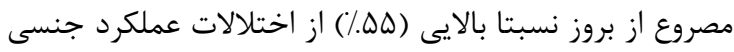

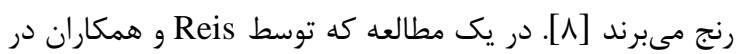

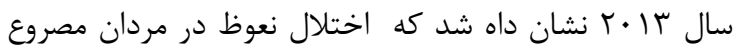

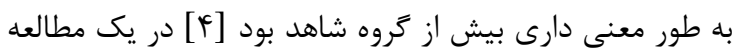

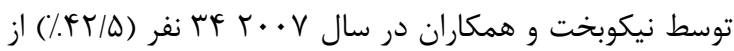

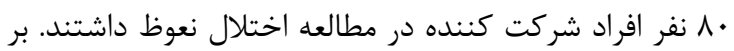

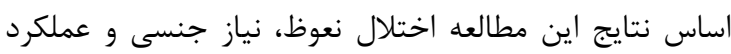

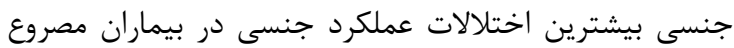

است [9].

مطالعات اندكى در كشور ما به بررسى اثرات داروهاى ضد

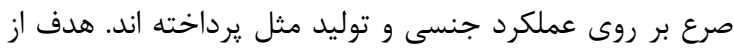

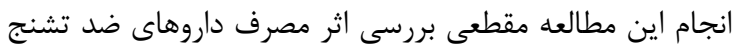

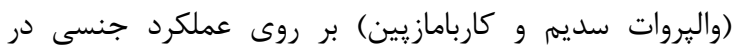

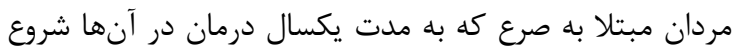

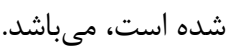

\section{مواد و روشها}

اين مطالعه به صورت مقطعى، در شهر همدان و سال

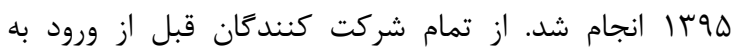

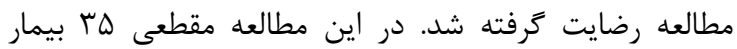

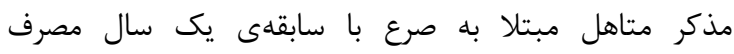

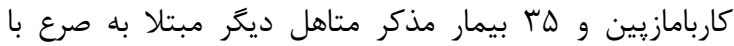

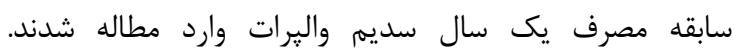

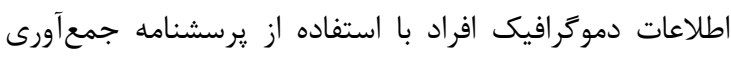




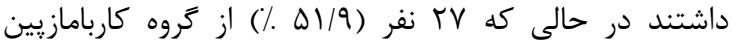

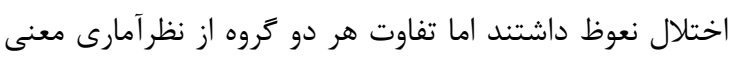

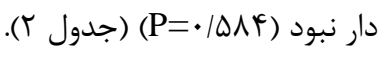

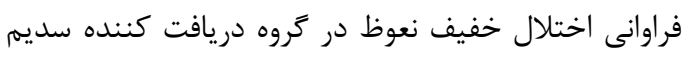
واليروات بيشتر از گروه كاربامازيين بود در حالى كه در اختلال متوسط تا خفيف و متوسط گروه كاربامازبين فراوانى بيشترى بئن

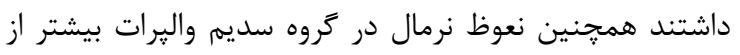

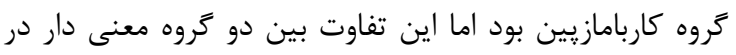

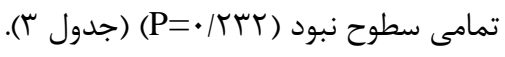

عملكرد جنسى در حالت كلى، عملكرد نعوظ، تعداد ارگاسم،

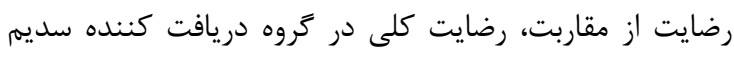

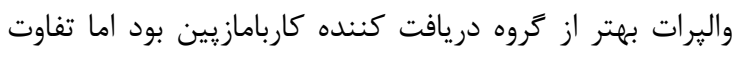

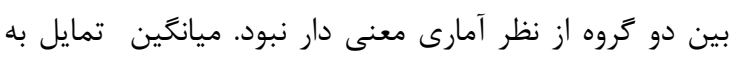

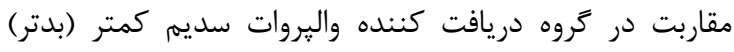

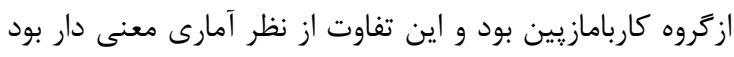
(جدول ( $(\mathrm{P}=\cdot 1 \cdot \mathrm{V})$

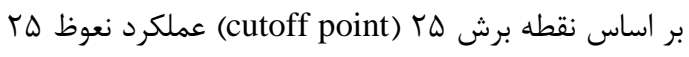

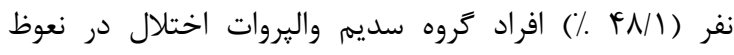

جدول ا: مقايسه ميانگين سنى و عملكرد جنسى كروه دريافت كننده سديم واليرات و كاربامازيين

\begin{tabular}{|c|c|c|c|}
\hline \multicolumn{2}{|c|}{ كاربامازيين } & \multicolumn{2}{|c|}{ سديم والبرات } \\
\hline P-value & انحراف معيار土 ميانكين & انحراف معيار土 ميانَين & متغير \\
\hline . MTQ & $T V / F T \pm Y / V I$ & TN/GT $\pm \Delta / \Delta T$ & سن (سال) \\
\hline$\cdot / \Delta N T$ & $\Delta) / 9 \Lambda \pm 1 r / 4 q$ & $\Delta r / F r \pm G / q r$ & عملكرد جنسى \\
\hline ./r१९ & $r \cdot / \Delta F \pm r / V r$ & $r \mid / \varepsilon r \pm r / V \Delta$ & تعداد نعوظ \\
\hline •/KTA & $V / \cdot \Delta \pm r / V \cdot$ & $V / \& T \pm r / F \Delta$ & تعداد اركاسم \\
\hline$\cdot / \pi \cdot 4$ & $q / r F \pm r / q F$ & $9 / 9 \Delta \pm 1 / \Delta \Delta$ & رضايت از مقاربت \\
\hline$\cdot 1990$ & $V / r) \pm r / 99$ & $\Lambda / \cdot \pm 1 / \Delta \mu$ & رضايت كلى \\
\hline$\cdot / \cdot V$ & $V / F T \pm 1 / 19$ & $8 / 01 \pm 1 / 1 r$ & تمايل به مقاربت \\
\hline
\end{tabular}

جدول r: مقايسه فراوانى اختلال نعوظ در دو گروه مطالعه

\begin{tabular}{|c|c|c|c|}
\hline \multicolumn{2}{|c|}{ كاربامازبين } & \multicolumn{2}{|c|}{ سديم واليرات } \\
\hline P-value & فراوانى (درصد) & فراوانى (درصد) & اختلال نعوظ \\
\hline \multirow{3}{*}{$\cdot \mid \Delta \Lambda A$} & $(\Delta / / 9) Y V$ & $(Y \wedge / I) Y \Delta$ & بلى \\
\hline & $(\mathcal{F} \wedge / 1) \wedge$ & $(\Delta) / 9) 1$. & خير \\
\hline & $(1 \cdot \cdot / \cdot) r_{\Delta}$ & $(1 \cdot \cdot / \cdot) r_{\Delta}$ & جمع \\
\hline
\end{tabular}

جدول ऍ: مقايسه شدت اختلال نعوظ بين دو گروه مطالعه

\begin{tabular}{|c|c|c|c|c|c|}
\hline \multicolumn{6}{|c|}{ اختلال نعوظ } \\
\hline P-value & بدون اختلال & خفيف & متوسط تا خفيف & متوسط & تروه \\
\hline & تعداد (درصد) & تعداد (درصد) & تعداد (درصد) & تعداد (درصد) & \\
\hline \multirow{3}{*}{ DTt } & $(\Delta \Delta / \varepsilon) 1$. & $(9 \wedge / \mathrm{V}) 11$ & $(\boldsymbol{F} \cdot / \cdot))$. & $(r q / F) F$ & سديم واليرات \\
\hline & $(\mathcal{F} F / \mathcal{F}) \wedge$ & $(\Gamma) / \Gamma) \Delta$ & $(9 \cdot 1 \cdot) 10$ & $(\Phi \mu / 9) V$ & كاربامازيين \\
\hline & $(1 \cdot \cdot / \cdot) \backslash 1$ & $(1 \cdot \cdot / \cdot) 119$ & $(1 \cdot \cdot) r \Delta$ & $(1 \cdot \cdot / \cdot) 11$ & جمع \\
\hline
\end{tabular}

سنى هر دو گروه مطالعه اختلاف آمارى معنى دارى نداشت

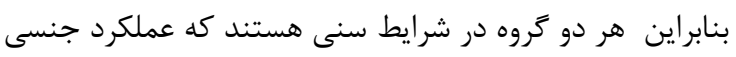

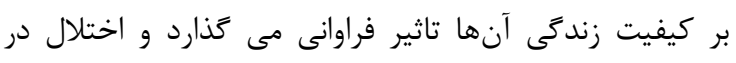
عملكرد جنسى مشاهده شده در آنها نمى تواند متاثر از شرايط سنى بيماران باشد. نتايج مطالعه حاضر نشان داد كه بهده ديماران

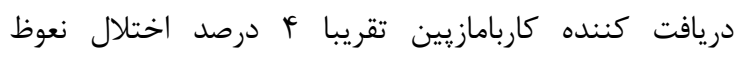
بيشترى داشتند اما تفاوت هر دو گروه از نظر آمارى معنى دار دينار

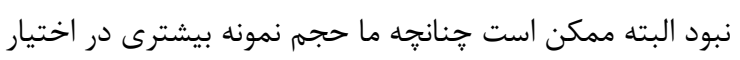

هدف از انجام اين مطالعه موردى- شاهدى مقايسه اثر

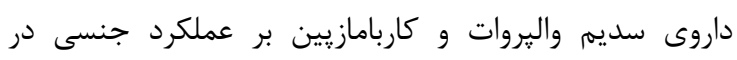

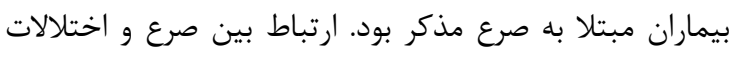

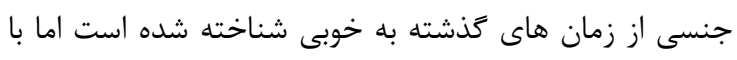

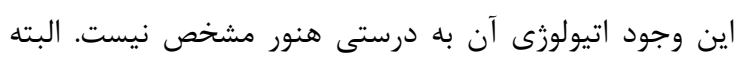

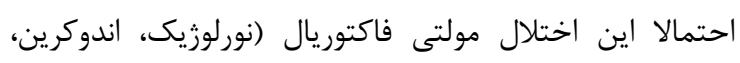

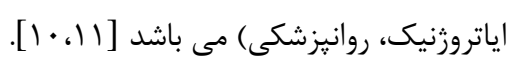

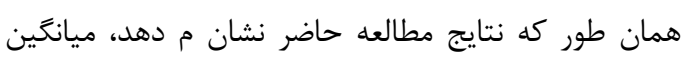


كاربامازيين بود اما تفاوت دو كروه معنىدار نبود. در كروه

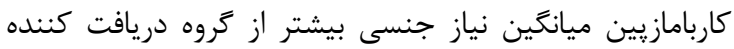

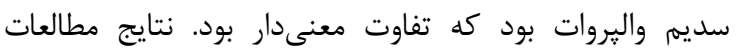

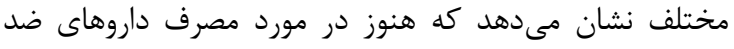

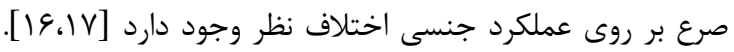

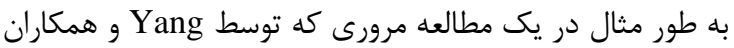

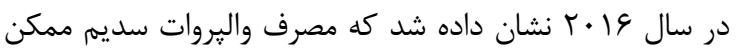
است باعث كاهش ليبدو شود در حالى كه كاربامازيين و و

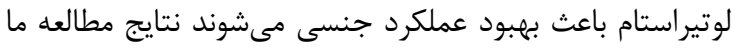

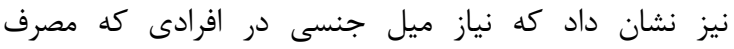

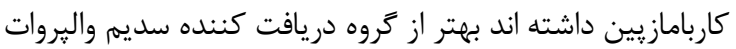

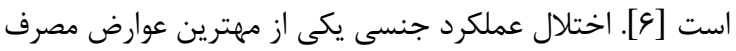

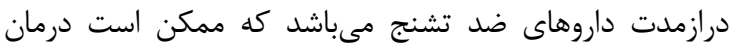

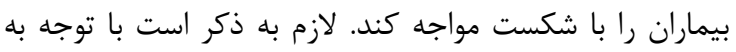

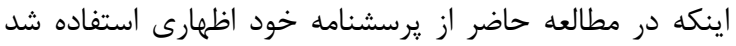
ممكن است پاسخهاى بيماران داراى اعتبار كافى نباشند.

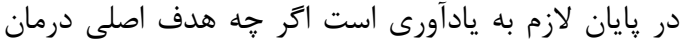

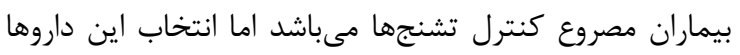

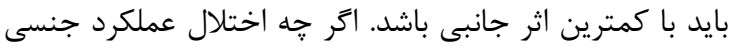

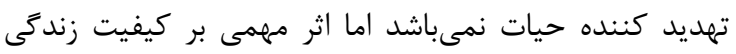

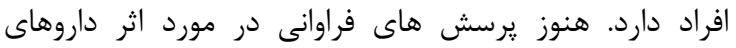

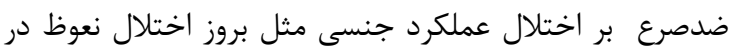

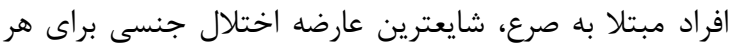

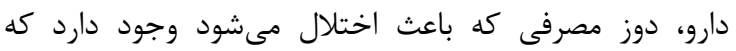

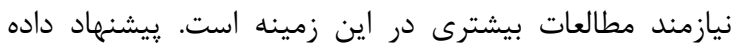

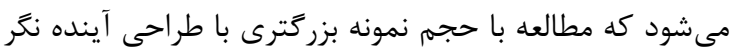

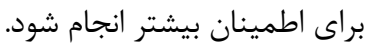

\section{نتيجه كيرى}

بر اساس نتايج اين مطالعه اختلال عملكرد جنسى در

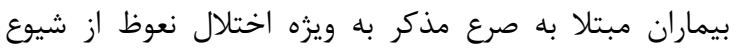

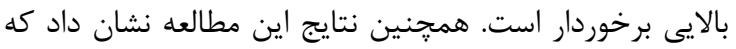

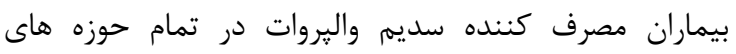

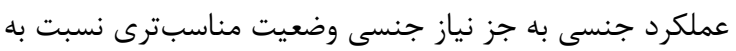
كروه كارباماز يِين دارند.

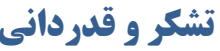

نويسندكان بر خود لازم مى دانند، از حمايتهاى مادى و و

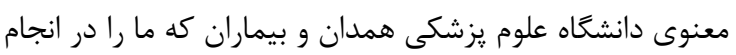
اين يزوهش يارى رساندند، تشكر و قدردانى نمايند.

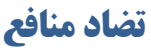
اين مطالعه هيجَّونه تضاد منافعى براى نويسندكان نداشته
داشتيم اين تفاوت معنى دار مىشد. فراوانى نعوظ نرمال و

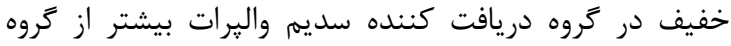

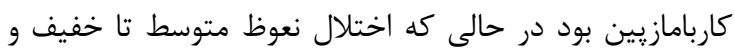

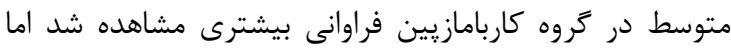

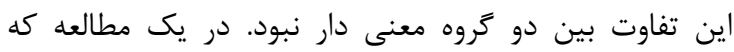

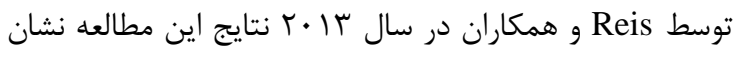
داد كه اختلال نعوظ در مردان كروه مورد بطور معنى دارى بـ بيش

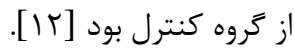
در يك مطالعه كه توسط نيكوبخت و همكاران انجام شد الـ

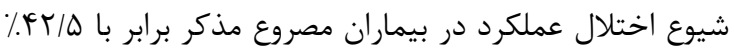

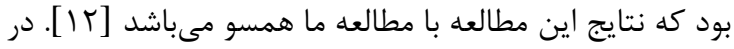

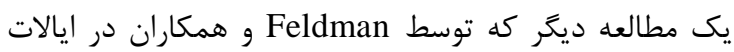

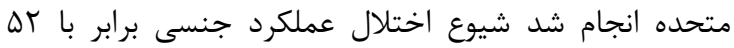

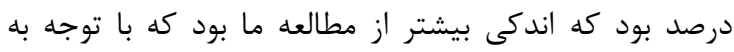

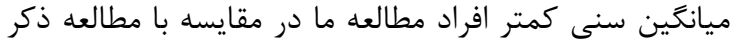

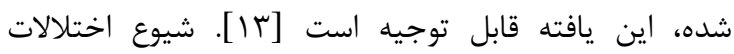

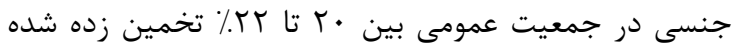

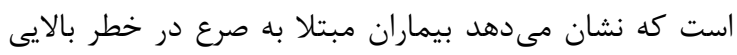

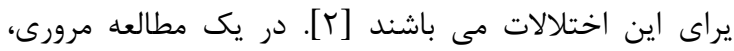

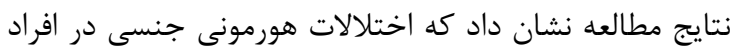

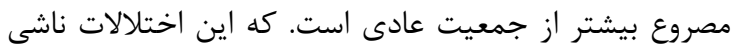

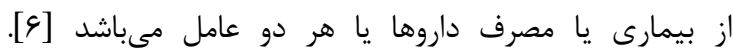

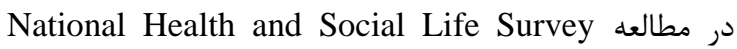
در مردان سالم با دامنه سنى 1) (تا وه سال اختلال (NHSLS)

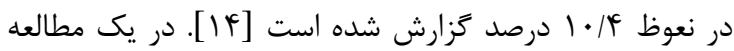

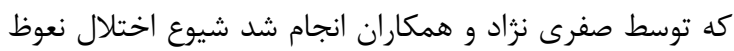

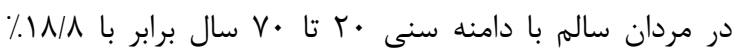

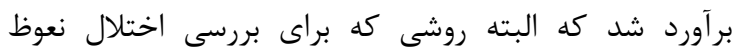

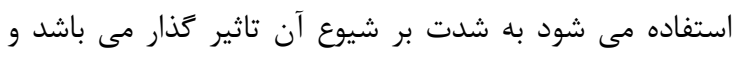

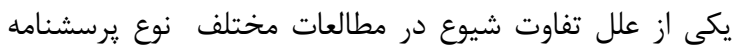

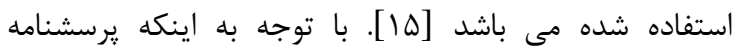

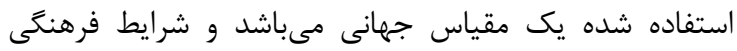

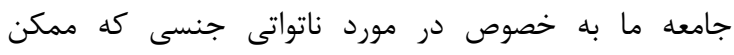

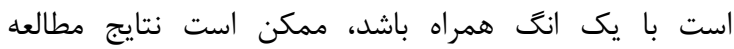

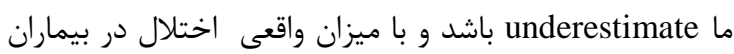
متفاوت باشد. بر اساس يافته مطالعه حاضر ميانكين نمره كلى

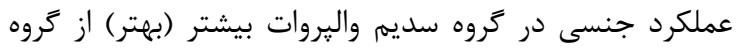

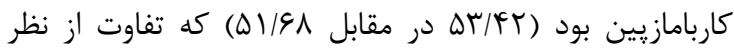

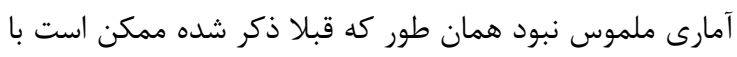

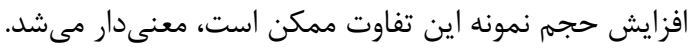

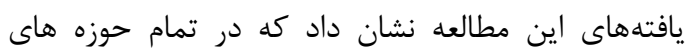

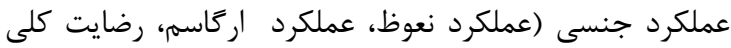
جنسى و رضايت از مقاربت) به جز نياز جنسى مئس ميانكين نمره

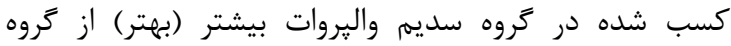




\section{REFERENCES}

1. Ropper AH, Samuels MA, Adams, Victor's. principles of neurology. 10 ed. New York: MC Graw Hill; 2013.

2. Rowland LP, Pedley TA. Merritt's Neurology. 12 ed. Houston: Lippincott Williams \& Wilkins; 2010.

3. Roullet FI, Lai JK, Foster JA. In utero exposure to valproic acid and autism--a current review of clinical and animal studies. Neurotoxicol Teratol. 2013;36:47-56.

4. Reis RM, de Angelo AG, Sakamoto AC, Ferriani RA, Lara LA. Altered sexual and reproductive functions in epileptic men taking carbamazepine. J Sex Med. 2013;10(2):493-9.

5. Cohen MJ, Meador KJ, Browning N, May R, Baker GA, Clayton-Smith J, et al. Fetal antiepileptic drug exposure: Adaptive and emotional/behavioral functioning at age 6years. Epilepsy Behav .2013;29(2):308-15.

6. Luef G, Madersbacher H. Sexual dysfunction in patients with epilepsy. Handb Clin Neurol. 2015;130:383-94.

7. Xiaotian X, Hengzhong Z, Yao X, Zhipan Z, Daoliang X, Yumei W. Effects of antiepileptic drugs on reproductive endocrine function, sexual function and sperm parameters in Chinese Han men with epilepsy. J Clin Neurosci. 2013;20(11):1492-7.

8. Heroz AG, Levesque LA, Drislane FW, Ronthal M, Schomer DL. Phenytoin-induced elevation of serum estradiol and reproductive dysfunction in men with epilepsy. Epilepsia. 1991;32(4):550-3.

9. Tang DD, Li C, Peng DW, Zhang XS. Validity of premature ejaculation diagnostic tool and its association with International Index of Erectile Function-15 in Chinese men with evidence-based-defined premature ejaculation. Asian J Androl. 2018; 20(1):19-23.
10. Burnham WM, Edwards HE. Intractable epilepsy, hormonal and reproductive problems: human and animal studies. Adv Neurol. 2006;97:351-5

11. Calabro RS, Grisolaghi J, Quattrini F, Bramanti P, Magaudda A. Prevalence and clinical features of sexual dysfunction in male with epilepsy: the first southern Italy hospital-based study. Int J Neurosci. 2013;123(10):732-7.

12. Nikoobakht M, Motamedi M, Orandi A, Meysamie A, Emamzadeh A. Sexual dysfunction in epileptic men. Urol J. 2007;4(2):111-7.

13. Feldman HA, Goldstein I, Hatzichristou DG. Impotence and its medical and psychosocial correlates: results of the Massachusetts Male Aging Study. J Urol. 1994;154:54-61.

14. Laumann EO, Paik A, Rosen RC. The epidemiology of erectile dysfunction: results from the National Health and Social Life Survey. Int J Impot Res. 1999;11:60-4.

15. Safarinejad MR. Prevalence and risk factors for erectile dysfunction in a population-based study in Iran. . Int J Impot Res. 2003;15:246-52.

16. Calabro RS, Marino S, Bramanti P. Sexual and reproductive dysfunction associated with antiepileptic drug use in men with epilepsy. Expert Rev Neurother. 2011;11(6):887-95.

17. Cappelleri JC, Rosen RC, Smith MD, Mishra A, Osterloh IH. Diagnostic evaluation of the erectile function domain of the International Index of Erectile Function. Urology. 1999;54(2):51-6.

18. Kuba R, Pohanka M, Zakopcan J, Novotna I, Rektor I. Sexual dysfunctions and blood hormonal profile in men with focal epilepsy. Epilepsia. 2006;47(12):2135-40. 